\title{
Processo de trabalho em enfermagem/ saúde no Sistema Único de Saúde
}

\author{
Valéria Lerch Lunardi ${ }^{1}$ \\ Wilson Danilo Lunardi Filho ${ }^{2}$ \\ Acélia Inês Schwengber ${ }^{3}$ \\ Carla Regina André Silva ${ }^{4}$
}

Objetiva-se apresentar o Sistema Único de Saúde (SUS) como uma proposta filosoficamente estruturada para contrapor-se às disfunções e distorções presentes no processo de trabalho em enfermagem/saúde decorrentes da influência do modo de produção capitalista e a tecnologia do cuidado como incorporação e expressão da proposta filosófica do SUS.

Descritores: Enfermagem, Saúde, Trabalho, Sistema Único de Saúde.

\section{Nursing work process/health in Unified Health System}

This paper aims to present the Unified Health System as philosophically structured proposal to contradict the dysfunctions and distortions existing in nursing working process/health as a result of the influence of capitalism and the technology of care as an incorporation and expression of the Public Health Program philosophical proposal.

Descriptors: Nursing, Health, Work, Unified Health System.

\section{Proceso de trabajo en enfermería/salud en El Sistema Unificado de Salud}

Este estudio tiene como objetivo presentar el Sistema Unificado de Salud (SUS) como una propuesta filosoficamente estructurada para contraporse a las disfuncciones y distorsiones presentes en el proceso de trabajo de enfermería/salud decurrentes de la influencia de la manera de producción capitalista y la tecnología del cuidado como incorporación y expresión de la propuesta filosófica del SUS.

Descriptores: Enfermería, Salud, Trabajo, Sistema Unificado de Salud.

\section{INTRODUÇÃO}

ए ste texto tem como objetivo apresentar o Sistema Único de Saúde (SUS) como uma proposta filosoficamente estruturada, para contrapor-se às disfunções e distorções presentes no processo de trabalho em enfermagem/ saúde decorrentes da influência do modo de produção capitalista e a tecnologia do cuidado como incorporação e expressão da proposta filosófica do SUS. Inicialmente, apresentam-se influências do modo de produção capitalista no processo de trabalho em enfermagem/saúde, e, a seguir, o SUS como uma proposta fundamentada em princípios ideológicos, organizacionais e de participação, finalizando com o cuidado como uma tecnologia da enfermagem/saúde que potencializa indivíduos e processos de trabalho.

\section{Influências do modo de produção capitalista no processo de trabalho em enfermagem/saúde}

Desde que o modo capitalista de produção desenvolveu-se, tornando-se hegemônico, foi destruindo e substituindo as antigas formas de cooperação social, comunitária e familiar. Transformou em mercadoria praticamente toda e qualquer atividade humana, inclusive aquelas que eram atendidas na forma tradicional pela própria família ou grupo comunitário, como as tarefas domésticas e os atos de cuidar ${ }^{(1)}$. O cuidado progressivamente foi sendo institucionalizado, apropriado e transformado tecnologicamente. Dessa maneira, o trabalho em saúde adquiriu o status de serviço a ser consumido, e, para isso, comprado.

Assim, quanto mais os membros da família exercem algum tipo de trabalho fora do lar, menos aptos e disponíveis para cuidarem uns dos outros se tornam. Se os vínculos de amizade, vizinhança e comunidade sofrem nova interpretação, numa escala mais estreita, para excluir responsabilidades onerosas, o cuidado de uns com os outros se torna mais institucionalizado. Nesse espaço é que se insere o trabalho dos profissionais da saúde, entre eles o dos profissionais de enfermagem, consoante as exigências e necessidades geradas pelo progressivo avanço do modo de produção a que está submetida e se submete a maior parte da população(2).

Transformando-se em trabalho, o cuidado humano em relação à saúde adquire características particulares, sendo desenvolvido por diferentes ramos de especialidades profissionais, nas quais diversos grupos de trabalhadores cooperam entre si, determinando relações entre eles, em torno do objeto, dos instrumentos de trabalho e dos produtos derivados dessas atividades. Nesse processo de trabalho em saúde mais amplo, as diversas atividades que o compõem são complementares, com maior ou menor grau de autonomia,

1 Enfermeira. Doutora em enfermagem. Professora associada II da Escola de Enfermagem da Universidade Federal do Rio Grande - EENF/Furg.

2 Enfermeiro. Doutor em enfermagem. Professor associado II da EENF/Furg.

3 Enfermeira. Mestre em enfermagem. Chefe de enfermagem do Hospital de Cardiologia da Associação de Caridade Santa Casa do Rio Grande.

4 Enfermeira. Mestre em enfermagem. Enfermeira do Hospital Universitário da Universidade Federal do Rio Grande - Furg. 
mas de um modo em que não há o mesmo parcelamento hierárquico de autoridade e de poder entre os agentes ${ }^{(1)}$.

Essa distribuição de autoridade ocorre pela subordinação dos executores aos mentores, de modo que as tarefas de determinado trabalho não se distribuem, apenas, em função de sua característica técnica, mas, também, de uma lógica de diferenciação social. A respeito do processo da enfermagem, é preciso entender que ele se realiza como um trabalho que se constitui no interior do trabalho em saúde, produzindo-se em sua relação com as demais profissões da saúde. Nessa articulação, reconhece-se sua complementaridade com outros trabalhos ${ }^{(3)}$.

Essa forma de organização do trabalho coletivo em saúde apresenta uma divisão técnica com características de manufatura, sendo sua lógica de qualificação, no interior do setor terciário, um serviço a ser consumido. Como serviço, o trabalho em saúde torna-se menos visível em todas as suas etapas, principalmente porque produto e consumo se confundem, pois o cliente configura-se, ao mesmo tempo, como o principal objeto de trabalho - um objeto-sujeito que, ao sofrer as ações dos trabalhadores da saúde, se torna ele mesmo o produto de tais ações realizadas. Ao usufruí-las durante as etapas constitutivas dos diversos processos de trabalho em saúde, já as usufrui na qualidade de consumidor. Portanto, torna-se mais complexa a análise desse trabalho, uma vez que o principal objeto - o ser humano - não é exclusivamente material, possuindo um atributo que lhe confere maleabilidade, incerteza, personalidade, ou seja, tem existência e história(2).

Desse modo, o processo de trabalho em saúde reúne um conjunto de atividades programadas e normatizadas, que se realizam à base de cooperação e, além disso, em um cenário dinâmico e instável(4). Ao voltar os olhos com atenção para os processos de trabalho que se produzem cotidianamente nas instituições/serviços de saúde, verificase que o conjunto das intervenções assistenciais, além dos vários materiais, instrumentos e máquinas usados, também se mobiliza intensamente na construção de um modo de produzir tecnologias, a partir dos processos relacionais e de saberes ${ }^{(5)}$.

Portanto, o trabalho em saúde se produz muito além das tecnologias entendidas como equipamentos, procedimentos e técnicas usadas nas intervenções realizadas junto aos pacientes nos serviços. Pois, qualquer que seja a abordagem, existirão sempre relações mediadas por uma pessoa atuando sobre outra, havendo, nesse processo de trocas, jogos de expectativas, momentos de fala, escuta e interpretações, nos quais existe a produção de vínculo, de uma acolhida ou não das intenções que esse encontro produz.

Grande parte dos trabalhadores da saúde sob a influência do modo hegemônico de produção vem sendo envolvida por um círculo vicioso em seus processos de trabalho. Eles desenvolvem rotinas extenuantes, realizando ações automatizadas e mecânicas, desfavorecendo as relações interpessoais tanto na produção quanto em um viver mais humanizado e saudável. Essa forma de exercício profissional dificulta e pode até inviabilizar a elaboração de estratégias no trabalho para promover sistemas saudáveis e sustentáveis, entendidos como uma composição de todos os seres vivos e ambientes, integrados em sua totalidade, de forma complexa e dinâmica, em um sentido de continuação e expansão como uma rede autossustentável. Nela, acontecem interconexões e interdependências, compartilhamentos e transferências de experiências, promovendo crescimento, desenvolvendo-se, assim, uma visão sistêmica e integral do todo ${ }^{(6-7)}$.

Em grande parte das instituições de saúde, pode-se observar que muitos de seus trabalhadores, imersos em uma cultura de fragmentação, não se percebem integrantes dessa rede. Tal fato parece influenciar sobremaneira o modo de estabelecerem as relações consigo e com os outros, nas posturas diversificadas e nos diferentes modos de agir, de assumir responsabilidades e comprometimento com a promoção da saúde e do cuidado da vida.

Ao apresentarem esse comportamento, deixam de ter como finalidade principal de seu trabalho a integralidade do cuidado às pessoas, conformando-se com um modelo de atuar referenciado no mecanicismo, sem relacionáloàsquestões da singularidadedoserhumano. Desse modo, nos diferentes ambientes onde se desenvolve a assistência à saúde, ainda parece predominar a sobreposição do modelo de cuidado individual ao coletivo, estando o cuidado essencialmente centrado na doença. Nessa concepção, a assistência à saúde torna-se objetivada, desconsiderando importantes aspectos da subjetividade humana, incentivando muito pouco a participação e a autonomia das pessoas como usuários, deixando-as em posição de meros coadjuvantes, quando também deveriam ser protagonistas do cuidado a sua saúde ${ }^{(6)}$.

Prova disso é que, apesar de os discursos sobre o autocuidado reforçarem a autonomia e a participação do paciente em seu cuidado ou no planejamento de sua assistência, a percepção e a abordagem do paciente como um sujeito capaz de pensar, de refletir, de conhecer e de optar, decidindo por si e para si como um ser dotado de razão, de vontade e de capacidade de exercer sua liberdade, parece ainda não se fazer de modo satisfatório. Isso porque o sujeito que determina o processo parece ainda ser predominantemente o profissional de saúde.

Por sua vez, a fragmentação do ser humano dificulta as ações de promoção e proteção da saúde e cuidado da vida, tanto dos usuários quanto dos próprios trabalhadores e gestores. Essa condição de divisibilidade gera conflitos, baixa capacidade de resolução, insatisfação com o atendimento recebido e prestado, o não-reconhecimento, o desrespeito e a desvalorização das necessidades das diferentes pessoas que atuam nesse contexto. Por sua vez, ao mecanizarem-se as relações, deixase de considerar cada pessoa como ser único e possuidor de sentimentos, experiências, passado, presente e futuro, ou seja, desconsideram-se características individuais que compõem a importância do e no todo de cada ser. 


\section{O SUS como uma proposta filosófica de contraposição às} disfunções e distorções no processo de trabalho em saúde

O SUS surgiu como uma proposta filosoficamente estruturada para contrapor-se às disfunções e distorções presentes no processo de trabalho em saúde decorrentes da influência do modo de produção capitalista, na forma da organização e do desenvolvimento dos diferentes processos de trabalho das profissões que o compõe. Anteriormente à promulgação das leis que confluíram para sua criação, a saúde da população era de responsabilidade do Ministério da Saúde, com ênfase na assistência médico-hospitalar. Os objetivos do atendimento eram centrados em tratar a doença, portanto bastante diferentes do que é amplamente preconizado pelo SUS. Além disso, as pessoas que não contribuíam para a Previdência Social eram consideradas e tratadas como indigentes, acentuando ainda mais as desigualdades sociais. As instituições filantrópicas é que as assistiam precariamente ${ }^{(8)}$.

Com vistas ao resgate dos valores humanos colocados em plano secundário no modo capitalista de produção, oSUSfundamenta-se, entreoutros, em princípios ideológicos ou doutrinários: universalidade, integralidade, equidade; princípios organizacionais: descentralização, hierarquização e regionalização dos serviços de saúde; e princípios de participação da comunidade ou controle social. Esses princípios ideológicos, organizacionais e de participação são os que melhor representam aspectos democráticos na promoção e produção de saúde preconizadas pelo SUS. A legislação contempla ainda outros princípios: a preservação da autonomia das pessoas, na defesa de sua integridade física e moral; o direito à informação sobre sua saúde; a divulgação de informações quanto ao potencial dos serviços de saúde e sua utilização pelo usuário; a epidemiologia como meio para o estabelecimento de prioridades; a alocação de recursos e a orientação programática; a integração em nível executivo das ações de saúde, meio ambiente e saneamento básico; a conjugação dos recursos financeiros, tecnológicos, materiais e humanos da União, dos estados, do Distrito Federal e dos municípios, na prestação de serviços de assistência à saúde da população; a resolução dos serviços em todos os níveis de assistência e organização dos serviços públicos, evitando duplicidade de meios para fins idênticos ${ }^{(9)}$.

O estado, como representante da população, tem o dever de defender os interesses de seus representados. Entretanto, para vivenciarmos essa realidade, se faz imprescindível a participação de todos, de forma integrada, interconectada, interdependente e responsável. Dizer que o Estado é responsável não exime o indivíduo e a sociedade de suas responsabilidades consigo mesmos, com os outros e com os ambientes ${ }^{(10-11)}$.

São de responsabilidade do SUS a promoção da saúde, priorizando a prevenção, em um processo democrático, propiciando à população conhecer seus direitos, deveres e os riscos a sua saúde e incentivando a participação popular; o controle do aumento e da propagação de doenças (Vigilância Epidemiológica); o controle da qualidade da água, do solo, do ar, de remédios, de exames, de alimentos, higiene e adequação de instalações que atendem ao público, onde atua a Vigilância Ambiental e Sanitária. Tem como grande meta constituir-se num importante mecanismo de promoção da equidade no atendimento das necessidades de saúde da população, ofertando serviços com qualidade, independentemente do poder aquisitivo, contribuição previdenciária ou concepção política do cidadão ${ }^{(9)}$.

Um dos maiores desafios do SUS é promover o exercício da autonomia e da cidadania do ser humano, tanto como usuário quanto como trabalhador da saúde. Precisa-se incentivar a práxis da saúde, buscando novas atitudes, posturas e comprometimento para que todos possam exercer tanto os direitos quanto os deveres assegurados na Constituição Federal. $E$ isso tendo em mente que a promoção da saúde e o cuidado da vida acontecem individual e coletivamente, envolvendo o país em uma compreensão que a saúde é um dever do Estado, mas que esse fato não extingue a responsabilidade individual, coletiva e social. Para isso, é preciso desenvolver ações e estratégias de assistência à saúde efetivas, eficientes e sustentáveis, em que usuários, trabalhadores, gestores e governantes lutem unidos pelos mesmos objetivos ${ }^{(11-14)}$.

Avaliando os resultados baseados nos registros de centros de pesquisa como a

Fundação Oswaldo Cruz (Fiocruz) e o Instituto Brasileiro de Geografia e Estatística (IBGE), entre outros, pode-se dizer que o SUS vem contribuindo para o alcance de melhorias na qualidade de vida da população, expressa nos indicadores de saúde nacionais e internacionais de desenvolvimento humano. Constitui o modelo oficial público de atenção à saúde em todo o território nacional, sendo considerado pela OMS, internacionalmente, como um dos maiores sistemas públicos de saúde do mundo e o único a garantir assistência integral e totalmente gratuita para a população. No entanto, ainda há lacunas, pois permanecem fragilidades em seu processo. Mas não se deve esquecer de que o SUS tem apenas cerca de duas décadas - jovem, portanto, para um programa tão amplo, em um país com tamanha diversidade cultural, geográfica e econômica e vasta extensão territorial. Um sistema que se encontra em fase de construção e da qual podemos e devemos participar não apenas como profissionais e usuários, mas como cidadãos $^{(15)}$.

\section{A tecnologia do cuidado como incorporação e expressão da proposta filosófica do SUS}

A lógica instrumental consoante ao modo de produção capitalista dá sustentação ao trabalho em saúde, que se apoia na fisiopatologia para o diagnóstico e a terapêutica e que obtém relativos sucessos, se a restauração biológica for considerada como resultado. Entretanto, se for observada a 
experiência, isto é, o significado do padecimento, o vivido existencialmente durante o processo, faz-se necessário pensar na forma como é estabelecido o cuidado e em suas associações com o processo de promoção da saúde, prevenção de doenças e recuperação da saúde.

O cuidado, como historicamente preconizado pela ciência da enfermagem e incorporado à proposta do SUS, não se faz à custa do trabalho rotineiro e tarefeiro, destituído de subjetividade. Ocorre, principalmente, mediante formas criativas, ousadas e prazerosas de entendê-lo e realizá-lo, contemplando responsabilidade e comprometimento pessoal, afetivo, social, moral e espiritual. Em outras palavras, o trabalho da enfermagem/saúde não pode ser uma simples reprodução de técnicas, fragmentado, impessoal e destituído de afeto, felicidade, alegria e solidariedade. Ele tem de produzir vínculos entre os diferentes protagonistas - pacientes, trabalhadores, gestores e instituições -, ou seja, precisa ser produtor de um tipo de acolhimento que potencialize as pessoas e os processos de trabalho, contribuindo para mudanças na concepção da saúde e do cuidado como um direito, inclusive do trabalhador ${ }^{(16)}$.

Assim, a tecnologia do cuidado se produzquandoa existência das pessoas se torna significativa, independentemente do papel que está ocupando (enfermeira, docente, equipe, paciente), numa perspectiva integrada. O sentimento de importância é a motivação para dedicar-se ao outro, para participar de seu destino, de suas buscas, seus sofrimentos, afetos, sucessos, avanços e mesmo seus fracassos e limites, numa expressão de compromisso com o outro.

Diagnosticar respostas humanas é um processo complexo, que requer conhecimento teórico, experiência prática, habilidade intelectual, técnica e de interação interpessoal, aplicados à observação, avaliação e interpretação do comportamento da pessoa relacionado à saúde e, portanto, à vida. O conteúdo e a complexidade do pensamento envolvido tanto no raciocínio e no julgamento clínico acerca das respostas humanas aos problemas de saúde ou aos processos vitais quanto no raciocínio e no julgamento terapêutico acerca do cuidado necessário ao paciente refletem os valores da profissão e o conhecimento que tem sido desenvolvido e acumulado em centenas de anos de prática de enfermagem, em vários campos de atuação - ensino, assistência, gerenciamento e pesquisa em enfermagem. A esse respeito, destacam-se dois aspectos. $\mathrm{O}$ primeiro deles é que, no âmbito da enfermagem, o ser humano é um todo complexo e indivisível e responde aos problemas de saúde ou aos processos vitais. $O$ segundo é que o cuidado profissional de enfermagem existe como resultado de um empreendimento humano e não como um fenômeno natural, pois ele é aprendido e não instintivo ${ }^{(17)}$.

Portanto, para abordar a singularidade do ser humano, é importante reconhecer que todos os seres humanos são diferentes, únicos, complexos e multidimensionais, necessitados de oportunidades iguais para se desenvolver. Não para serem considerados iguais, mas para reconhecer e aceitar as diferenças e entender que todos os indivíduos têm o direito de ser respeitados em sua singularidade ${ }^{(18)}$. Ou seja, o sujeito a ser cuidado como outro é único. É preciso valorizar sua unicidade e entender que ele é um ser humano que se apresenta como alguém com uma história, necessidades, sentimentos e pensamentos próprios. Quando o outro não é tratado como sujeito e como alguém que é diferente, diferente até no que se pensa dele, nega-se a ele o direito de ser ele próprio, negandoIhe a possibilidade de ser humano.

\section{Referências}

1. Braverman H. Trabalho e capital monopolista - a degradação do trabalho no

século XX. $3^{\mathrm{a}}$ ed. Rio de Janeiro: Guanabara Koogan; 1987.

2. Lunardi Filho WD, Leopardi MT. O trabalho da enfermagem - sua inserção na

estrutura do trabalho geral. Rio Grande: Edgrafurg; 1999.

3. Schwengber Al. Processo de enfermagem: instrumento para o enfermeiro

administrar o trabalho e liderar a equipe de enfermagem [dissertação]. Rio

Grande: Universidade Federal do Rio Grande; 2008.

4. Pinho DLM, Abrahão Jl. As estratégias e a gestão da informação no trabalho de enfermagem no contexto hospitalar. Rev Latinoam Enferm. 2003;11(2):168-76. 5. Merhy EE. Saúde - a cartografia do trabalho vivo. São Paulo: Hucitec; 2002. 6. Silva CRA. Acolhimento: uma construção transversal, ética, estética e política na saúde [dissertação]. Rio Grande: Universidade Federal do Rio Grande; 2009. 7. Capra F. Teia da vida. $11^{2}$ ed. São Paulo: Cultrix; 2006.

8. Bertone AA. As ideias e as práticas: a construção do SUS [Internet]. [citado em 2008 Mai 13]. Disponível em HTTP://bvsms.saude.gov.br/bvs/publicacoes/ monografiarevisadaArnaldo.pdf.

9. Ministério da Saúde (BR). Lei orgânica 8080 de 1990 [Internet]. [citado em 2008 Mai 13]. Disponível em: http://200.214.130.38/portal/arquivos/pdf/Lei8080pdf. 10. Ministério da Saúde (BR). Lei orgânica 8142 de 1990 [Internet]. [citado em 2008 Mai 13]. Disponivel em: http://200.214.130.38/portal/arquivos/pdf/Lei8142.pdf.
11. Mezzomo AA. Fundamentos da humanização hospitalar: uma visão multidisciplinar. São Paulo: Loyola; 2003.

12. Ministério da Saúde (BR). Sistema único de saúde (SUS): princípios e conquistas. Brasilia: Ministério da Saúde; 2000.

13. Ministério da Saúde (BR). Conselho Nacional de Secretários Municipais de Saúde. O SUS de A a Z: garantindo saúde nos municípios. Brasilia: Ministério da Saúde; 2005.

14. Ministério da Saúde (BR). Conselho Nacional de Secretários Municipais de Saúde. O desenvolvimento do Sistema Único de Saúde: avanços, desafios e reafirmação dos princípios e diretrizes. Brasília: Ministério da Saúde; 2003. 15. Ministério da Saúde (BR). Secretaria Nacional de Assistência à Saúde. Humaniza SUS: documento básico para gestores e trabalhadores do SUS. $3^{\mathrm{a}}$ ed. Brasilia: Ministério da Saúde; 2006.

16. Lima RCD. O processo de cuidar na enfermagem: mudanças e tendências no mundo do trabalho. Cogitare Enferm. 2005;10(5):63-7.

17. Carvalho EC, Garcia TR. Processo de enfermagem: raciocínio e julgamento clínico no estabelecimento do diagnóstico de enfermagem. In: III Fórum Mineiro de Enfermagem, 2002, Uberlândia - MG. Sistematizar o cuidar: Anais. Uberlândia: UFU, 2002. p. 29-40.

18. Canguilhem G. O normal e o patológico. Rio de Janeiro: Forense-Universitária; 1982. 